\title{
A New DTC-SVM Based Control of Field Oriented Position Sensorless Induction Motor Drive with Reduced Torque and Flux Ripple
}

\author{
Md. Habibullah, Md. Jahirul Islam, Md. Abdur Rafiq, Kalyan Kumar Halder, and B. C. Ghosh
}

\begin{abstract}
Direct Torque Control (DTC) is widely used for ac drives. Attempts to combine DTC with Space Vector Modulation (SVM) have led to new ways. A new approach to DTC-SVM is presented in this paper. A Correlated Real Time Recurrent Learning (CRTRL) algorithm based Recurrent Neural Network (RNN) is used to estimate stator and rotor flux. Through measurement of the phase flux linkages and phase currents the RNN is able to estimate the rotor position, thereby facilitating elimination of the rotor position sensor. Fast dynamic speed response is obtained through maintaining the rotor flux constant as in the case of field orientation control. The control method proposed in this paper can reduce the torque, stator current, and rotor flux ripples which improve the system dynamic performance and robustness in different operating conditions. The proposed controller is also computationally efficient. The control methodologies and simulation results are given and discussed.
\end{abstract}

Index Terms-Direct torque control, space vector modulation, induction motor, flux estimation, torque ripple, flux ripple.

\section{INTRODUCTION}

It is well known that DTC system operates to control the stator flux and the torque directly by selecting the appropriate inverter switching state. DTC is also very simple in its implementation because it needs only two hysteresis comparators and switching vector table for both flux and torque control. Therefore, the only gains to be adjusted are the amplitudes of the hysteresis band. The amplitude of the hysteresis band greatly influences the drive performance such as flux and torque ripples, inverter switching frequency, and current harmonics [1], [2]. Current Researchers are working to maintain constant switching frequency in DTC and to reduce the torque, flux, current, and speed pulsations during steady state [3]-[5]. For minimizing torque and flux

Manuscript received August 26, 2010; revised January 5, 2011.

M. Habibullah is with the Electrical and Electronic Engineering Department, Khulna University of Engineering and Technology, Khulna, Bangladesh (Corresponding author to provide phone: +8801731171757 , e-mail: mhueeekuet@gmail.com).

M. J. Islam is with the Electrical and Electronic Engineering Department, Khulna University of Engineering and Technology, Khulna, Bangladesh (e-mail: jahirul_kuet@yahoo.com)

M. A. Rafiq is with the Electrical and Electronic Engineering Department, Khulna University of Engineering and Technology, Khulna, Bangladesh (e-mail: mdabdurrafiq2003@ yahoo.com).

K. K. Halder is with the Electrical and Electronic Engineering Department, Khulna University of Engineering and Technology, Khulna, Bangladesh (e-mail: kalyan_kuet@yahoo.com)

B. C. Ghosh is with the Electrical and Electronic Engineering Department, American International University-Bangladesh, Dhaka, Bangladesh (e-mail: bcgkuet@aiub.edu). ripple further new DTC-SVM scheme was proposed in [6], [7]. In [6], the DTC-SVM scheme in rotor flux reference frame is presented where the Auto Disturbance Rejection Controller (ADRC) is employed. In [7], a general Space Vector Pulse Width Modulation (SVPWM) algorithm is presented to reduce the torque and flux ripple. Both researchers of [6] and [7] used 3-level inverters for better performance rather than two level inverters.

High performance induction motor drives based on "Field Orientation" have been commercially available for almost three decades. Because of torque flux decoupling, Field Orientation Control (FOC) achieved good dynamic response and accurate motion control. Their performance is such that they can easily replace DC drives without loss of accuracy, stability or speed of response. The most significant barrier to further utilization is at present the rotor position sensor which being external to the controller- power electronics assembly. It is the cause of low reliability, high maintenance and high installation cost. So, demands for fast and accurate rotor position estimator in high performance motor drives are increasing. A number of model-independent solutions for sensorless speed and position control of induction motors have been developed [8]-[11]. However in these studies, the drives were limited to operation by flux saturation in the main path and around the rotor slots of the machine which interferes with that of the position-dependent rotor saliency. Unwanted "saturation harmonics" in the motor currents can dominate over the desired "position harmonic" making position estimation impossible [12].

In this paper, a new DTC-SVM based control of induction motor drive is presented. The inverter switch position is selected combining with the situation of torque error, current error and the position of stator flux angle. The rotor flux is estimated from induction motor currents and speed information. The proposed CRTRL algorithm is used to estimate the rotor flux with its angle and eliminates the rotor position sensor. The main flux saturation effects using a variable magnetizing inductance are also in consideration. The magnetizing inductance is expressed as a polynomial for a more realistic representation of a saturated induction machine. It is demonstrated that the proposed control scheme is robust against the external disturbance in various operating conditions.

\section{MATHEMATICAL MODEL}

The dynamic model of induction motor can be represented in the synchronous reference frame $(\mathrm{d}-\mathrm{q})$ as:

$$
v_{d s}=\left(R_{s}+p L_{s}\right) i_{d s}-L_{s} \omega_{e} i_{q s}+p L_{m} i_{d r}-L_{m} \omega_{e} i_{q r}
$$




$$
\begin{gathered}
v_{q s}=\omega_{e} L_{s} i_{d s}+\left(R_{s}+p L_{s}\right) i_{q s}+L_{m} \omega_{e} i_{d r}+p L_{m} i_{q r} \\
0=p L_{m} i_{d s}-\omega_{s l} L_{m} i_{q s}+\left(R_{r}+p L_{r}\right) i_{d r}-L_{r} \omega_{s l} i_{q r} \\
0=L_{m} \omega_{s l} i_{d s}+p L_{m} i_{q s}+\left(R_{r}+p L_{r}\right) i_{q r}+L_{r} \omega_{s l} i_{d r} \\
T_{e}=J p \omega_{m}+B \omega_{m}+T_{L}
\end{gathered}
$$

where,

$v_{d s}$ and $v_{q s}=$ the dq-axis stator voltages; $i_{d s}$ and $i_{q s}=$ the dq-axis stator currents; $i_{d r}$ and $i_{q r}=$ the dq-axis rotor currents; $R_{s}$ and $R_{r}=$ the stator and rotor resistances; $L_{s}$ and $L_{r}=$ the stator and rotor leakage inductances; $L_{m}=$ the mutual inductance; $\omega_{e}=$ the synchronous reference speed; $\omega_{r}=$ the rotor angular speed; $\omega_{m}=$ the angular speed of the motor; $\omega_{s l}\left(=\omega_{e}-\omega_{r}\right)=$ the slip angular speed; $T_{L}=$ the load torque; $J=$ the moment of inertia; $B=$ the rotational damping coefficient; $P_{p}=$ the number of pole pairs; $p \equiv$ $d / d t$.

The developed electromagnetic torque in terms of $d$ - and $q$ - axes components is given by:

$$
T_{e}=\frac{3}{2} P_{p} L_{m}\left(i_{q s} i_{d r}-i_{d s} i_{q r}\right)
$$

where $P_{p}$ is the number of pole pairs.

Components of rotor flux are:

$$
\begin{gathered}
\psi_{d r}=L_{r} i_{d r}+L_{m} i_{d s} \\
\psi_{q r}=L_{r} i_{q r}+L_{m} i_{q s}
\end{gathered}
$$

From (7) and (8), $d$ - and $q$ - axes rotor currents are:

$$
\begin{aligned}
i_{d r} & =\frac{1}{L_{r}}\left(\psi_{d r}-L_{m} i_{d s}\right) \\
\omega_{m}^{*} \quad i_{q r} & =\frac{1}{L_{r}}\left(\psi_{q r}-L_{m} i_{q s}\right)
\end{aligned}
$$

Substituting (7)-(10) into (3) and (4) yields:

$$
\begin{aligned}
& \frac{d \psi_{d r}}{d t}+\frac{R_{r}}{L_{r}} \psi_{d r}-\frac{L_{m}}{L_{r}} R_{r} i_{d s}-\omega_{s l} \psi_{q r}=0 \\
& \frac{d \psi_{q r}}{d t}+\frac{R_{r}}{L_{r}} \psi_{q r}-\frac{L_{m}}{L_{r}} R_{r} i_{q s}+\omega_{s l} \psi_{d r}=0
\end{aligned}
$$

If the field orientation is established such that $q$-axis rotor flux is set zero, and $d$-axis rotor flux is maintained constant then equations (11), (12), (9), (10) and (6) becomes:

$$
\begin{gathered}
\psi_{d r}=L_{m} i_{d s} \\
\omega_{s l}=\frac{1}{\tau_{r}} \frac{i_{q s}}{i_{d s}} \\
i_{d r}=0 \\
i_{q r}=-\frac{L_{m}}{L_{r}} i_{q s} \\
T_{e}=\frac{3}{2} P_{p} \frac{L_{m}}{L_{r}} \psi_{d r} i_{q s}
\end{gathered}
$$

Where $\tau_{r}\left(=L_{r} / R_{r}\right)$ is the time constant of the rotor. Hence, only $q$-axis stator current controls the developed electromagnetic torque.

Substituting (13) and rearrangement of (1) and (2), yields: $v_{d s}=R_{s} i_{d s}+\frac{L_{s}}{L_{m}} \frac{d \psi_{d r}}{d t}+L_{m} \sigma \frac{d i_{d r}}{d t}-\omega_{e} \frac{L_{m}}{L_{r}} \psi_{q r}-\omega_{e} \sigma L_{s} i_{q s}$

$$
v_{q s}=R_{s} i_{q s}+L_{s} \sigma \frac{d i_{q s}}{d t}+\omega_{e} L_{s} i_{d s}+\frac{L_{m}^{2}}{L_{r}} \frac{d i_{q s}}{d t}+\omega_{e} L_{m} i_{d r}+L_{m} \frac{d i_{q r}}{d t}
$$

where $\sigma=1-\frac{L_{m}^{2}}{L_{s} L_{r}}$ and $\omega_{e}=P_{p} \omega_{m}+\omega_{s l}$.

\section{Proposed CONTROL SCHEME}

In the proposed scheme shown in Fig. 1, the reference torque $T e^{*}$ is generated from speed error maintaining minimum time control [13] to get the fast speed response. The two errors in $i_{d s}$ and $i_{q s}$ are processed through two PI controllers to generate reference voltages $v_{d s}^{*}$ and $v_{q s}^{*}$. The stator command currents and command voltages are generated as follows:

$$
\begin{gathered}
i_{d s}^{*}=\Psi_{r}^{*} / L_{m} \\
i_{q s}^{*}=k_{p 1} \tau+k_{i 1} \int \tau d t \\
v_{d s}^{*}=k_{p 2}\left(i_{d s}^{*}-i_{d s}\right)+k_{i 2} \int\left(i_{d s}^{*}-i_{d s}\right) d t \\
v_{q s}^{*}=k_{p 3}\left(i_{q s}^{*}-i_{q s}\right)+k_{i 3} \int\left(i_{q s}^{*}-i_{q s}\right) d t
\end{gathered}
$$

Here, $\tau$ is the torque error.

The angle of the input stator voltage needed with respect to the reference stator $\alpha$-axis as:

$$
\hat{\theta}_{s}=\hat{\theta}_{v}+\hat{\theta}_{r} \text { where, } \hat{\theta}_{v}=\tan ^{-1}\left(v_{q s}^{*} / v_{d s}^{*}\right) .
$$

The magnetizing inductance representing the saturation in the magnetic circuit is given in the appendix and was found from the laboratory test of the motor. 


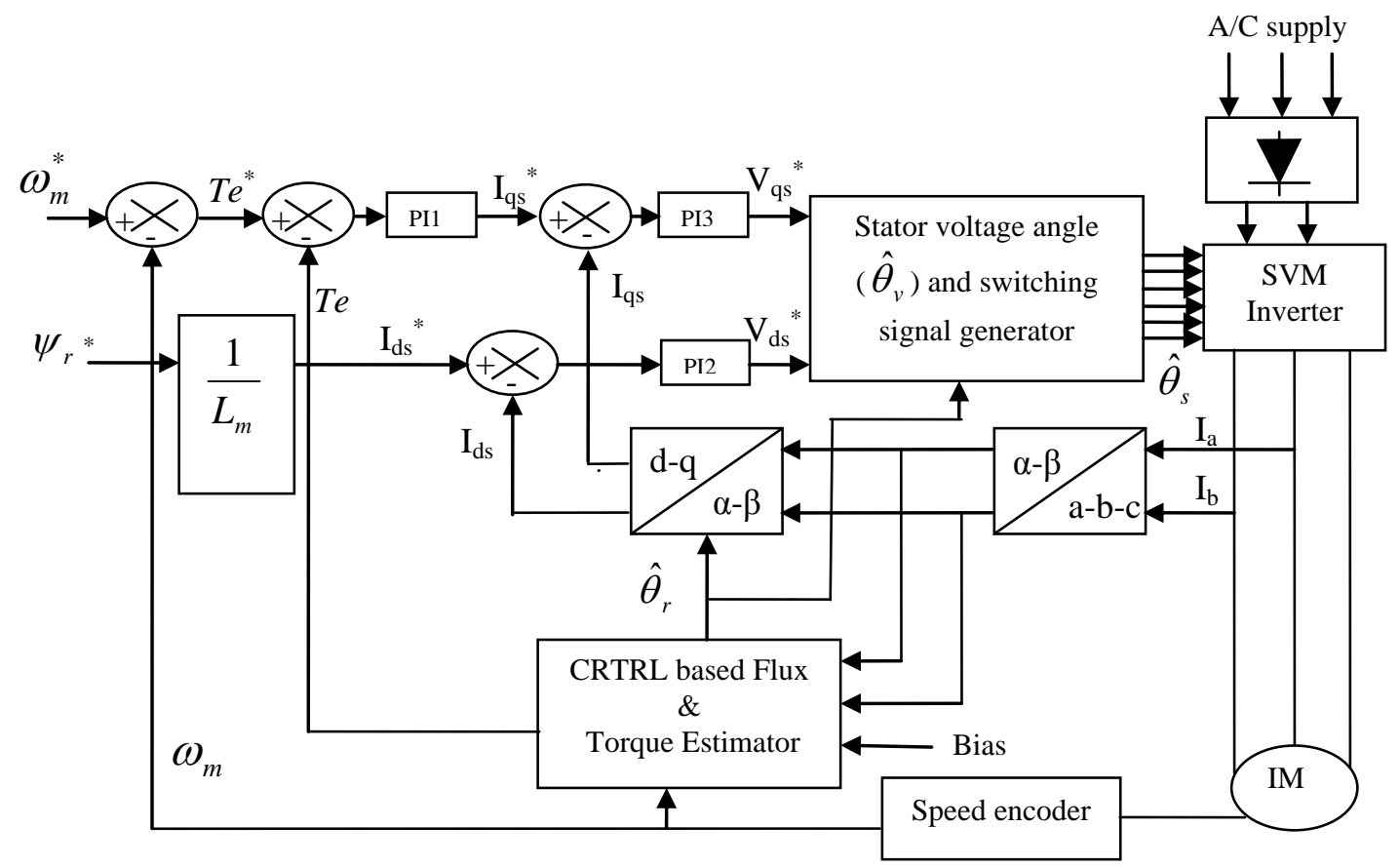

Fig. 1. Proposed control scheme

\section{CRTRl BASED FluX ESTIMATOR}

The CRTRL algorithm [14] is used to train the RNN based flux estimator. The fully connected RNN consists of $q$ neurons with $l$ external inputs, as shown in Fig. 2. Let the $q$-by-1 vector $\mathbf{x}(k)$ denotes the state of the network in the form of a nonlinear discrete-time system, the $(l+1)$-by-1 vector $\mathbf{u}(k)$ denotes the input (including bias) applied the network, and the $p$-by- 1 vector $\mathbf{y}(k)$ denotes the output of the network.

The process equation in the state-space description of the network is written in the following form:

$$
x(k+1)=\left[\begin{array}{c}
\varphi\left(W_{1}^{T}(k) z(k)\right) \\
\varphi\left(W_{2}^{T}(k) z(k)\right) \\
\vdots \\
\varphi\left(W_{q}^{T}(k) z(k)\right)
\end{array}\right]
$$

where $\varphi(\cdot)$ is an activation function, and the $(q+l+1)$-by-1 weight vector $W_{i}(k)$, which is connected to the $i$ th neuron in the recurrent network, corresponds to the $i$ th column of the transposed weight matrix $W^{T}(k)$.

The adjustment for the weight vector of the $i$ th neuron, $\Delta W_{i}$, is given by:

$$
\Delta W_{i}=\eta \frac{\partial J(k)}{\partial W_{i}(k)}=\eta C \Lambda_{i}(k) e(k), \quad i=1,2,3, \ldots . ., q
$$

where $J(k)$ is the cost function, $e(k)$ is the p-by-1 error vector.

The recursive equation $\Lambda_{i}$ for the neuron $i$ can be obtained by:

$$
\Lambda_{i}(k+1)=\varphi(k+1)\left[W_{x}(k) \Lambda_{i}(k)+Z_{i}(k)\right]
$$

Where $Z_{i}(k)$ is a $q$-by- $(q+l+1)$ matrix and $\varphi(k)$ is a $q-b y-q$ diagonal matrix defined by:

$$
\begin{aligned}
& \varphi(k+1)=\operatorname{diag}\left[\varphi^{\prime}\left(W_{1}^{T}(k) z(k)\right), \varphi^{\prime}\left(W_{2}^{T}(k) z(k)\right),\right. \\
& \left.\varphi^{\prime}\left(W_{q}^{T}(k) z(k)\right)\right]
\end{aligned}
$$

Stator flux synthesis by CRTRL algorithm is shown in Fig. 2. After getting the stator fluxes, $\Psi_{\alpha s}$ and $\Psi_{\beta s}$, the rotor fluxes, $\Psi_{\alpha r}$ and $\Psi_{\beta r}$ are obtained by the following equations:

$$
\begin{aligned}
& \Psi_{\alpha r}=\frac{L_{r} \Psi_{\alpha s}-\left(L_{s} L_{r}-L_{m}^{2}\right) i_{\alpha s}}{L_{m}} \\
& \Psi_{\beta r}=\frac{L_{r} \Psi_{\beta s}-\left(L_{s} L_{r}-L_{m}^{2}\right) i_{\beta s}}{L_{m}}
\end{aligned}
$$

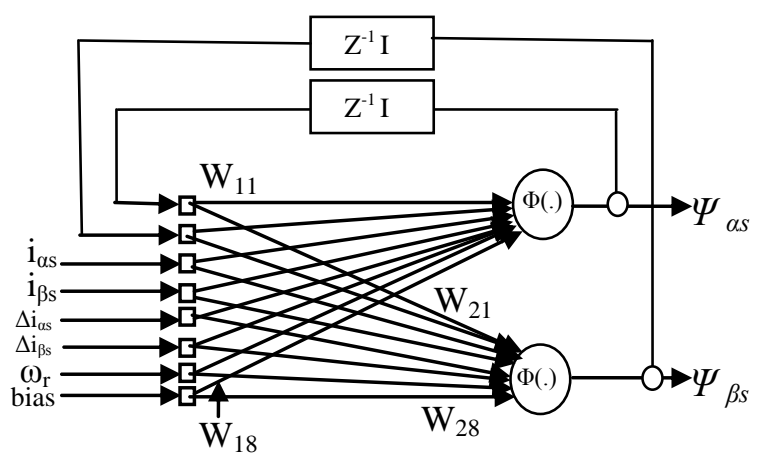

Fig. 2. Stator flux synthesis by CRTRL algorithm based RNN

\section{Simulation Results}

The proposed control structure was implemented in the environment software $\mathrm{C}++$, and tested with various operating conditions, to illustrate the performance of the proposed control scheme. The flux estimator was trained off-line so that it estimates the flux components accurately. The numerical method for solving the equations is Runge -Kutta method (order 4). The parameters of the induction motor used are given in the appendix.

\section{A. Stator flux and rotor position estimation}


Figs. $3 \& 4$ show the actual and estimated $\alpha$-axis stator flux, $\beta$-axis stator flux, and rotor flux angle under both in transient and steady state condition. It is apparent that the estimated responses are matching accurately with the actual responses both in transient and steady-state conditions. Thus the acceptability of the proposed CRTRL has been confirmed.

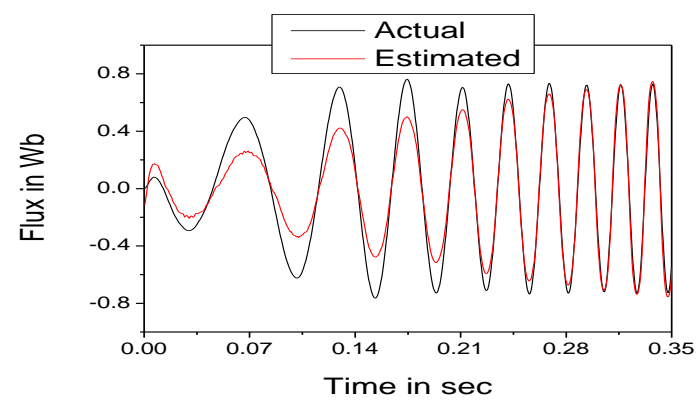

(a)

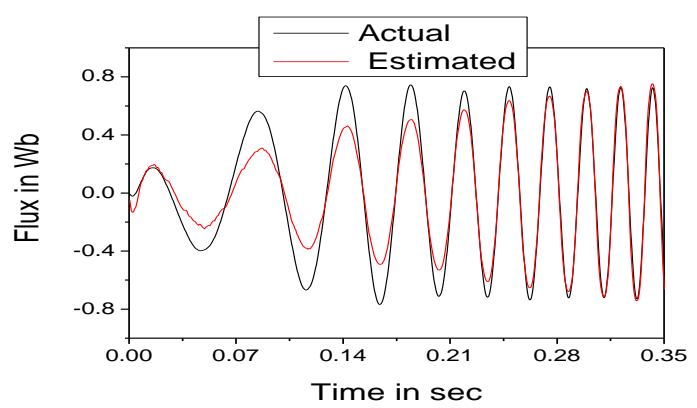

(b)

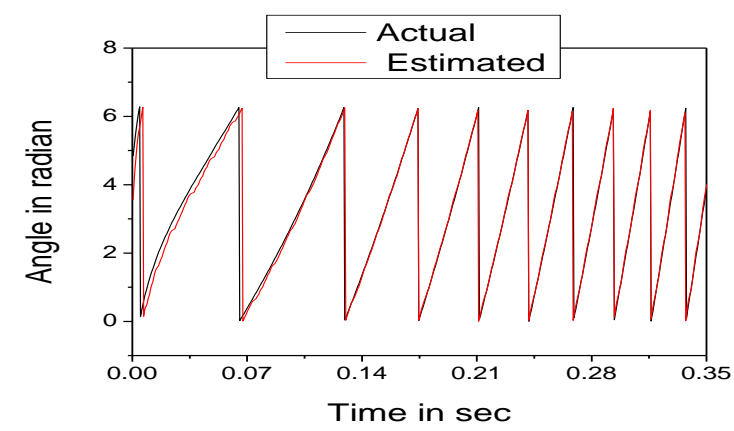

(c)

Fig. 3. Actual and estimated responses of (a) $\alpha$-axis stator flux, (b) $\beta$-axis stator flux, and (c) rotor angle for the induction motor drive under transient

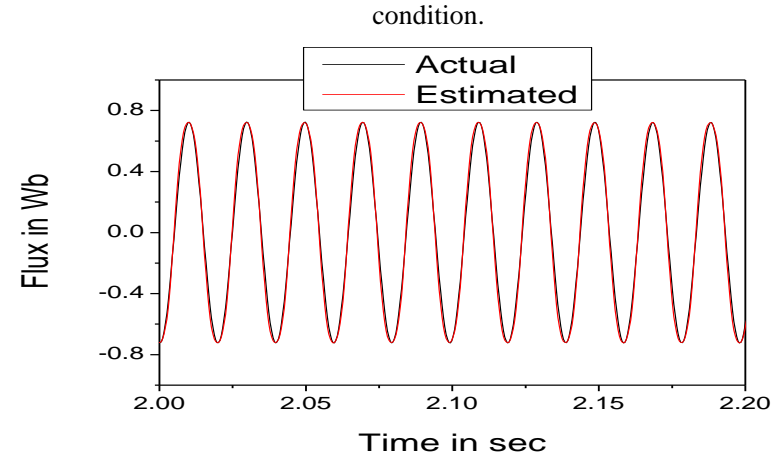

(a)

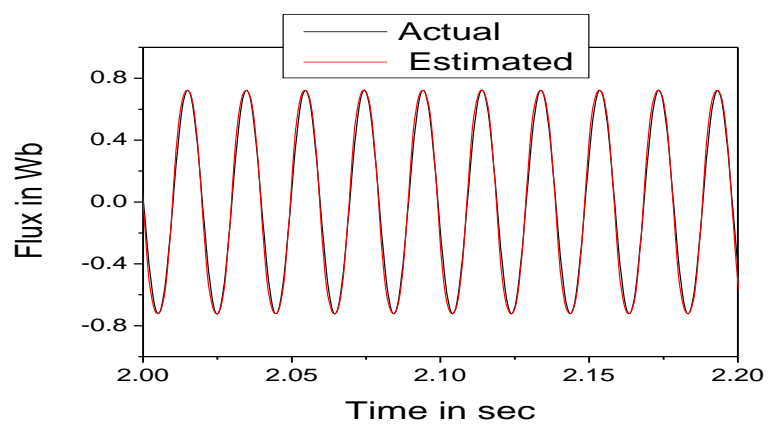

(b)

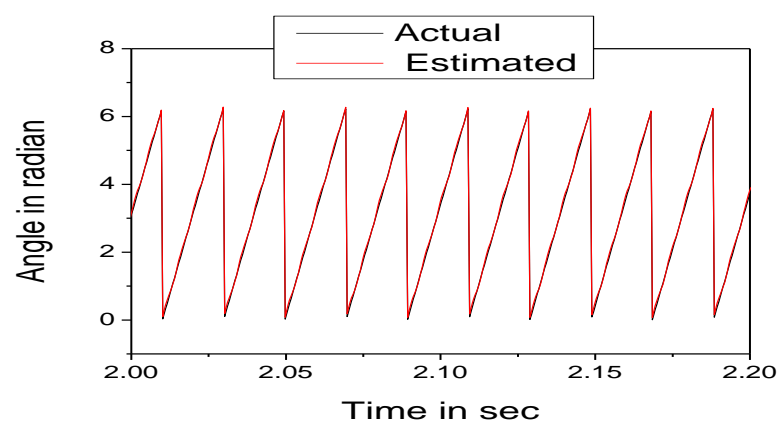

(c)

Fig. 4. Actual and estimated responses of (a) $\alpha$-axis stator flux, (b) $\beta$-axis stator flux, and (c) rotor angle for the induction motor drive under steady-state condition

\section{B. Starting Performance of the Induction Motor Drive}

The motor was started with a command speed of $1432 \mathrm{rpm}$ $(150 \mathrm{rad} / \mathrm{sec})$ with no load from standstill condition. At $\mathrm{t}=0.24$ second the motor reaches to the command speed as shown in Fig. 5(a). The motor follows the command speed accurately without steady-state error and oscillations. It can also be seen from Fig. 5(b) that, the developed electromagnetic torque is almost ripple free. In Fig. 5(c), it is observed that the rotor flux also follows the reference flux accurately. The stator phase currents are shown in Fig. 5(d). So the drive operates perfectly with negligible torque, flux, and current ripples.

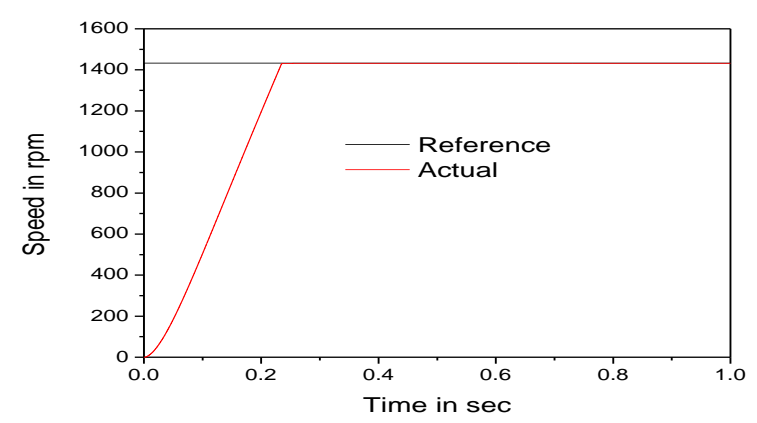

(a) 


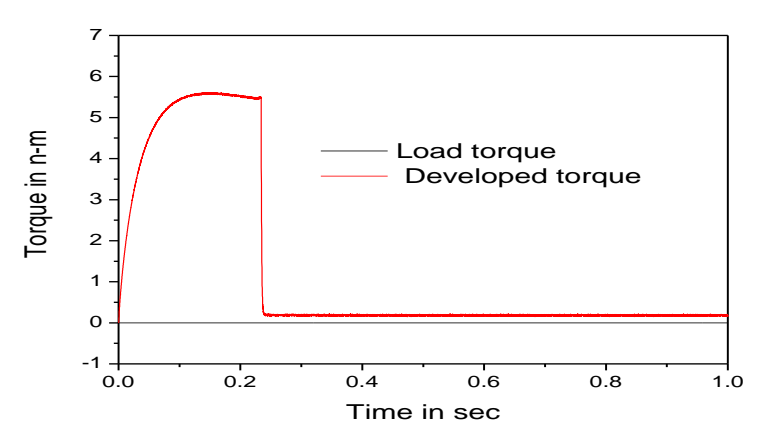

(b)

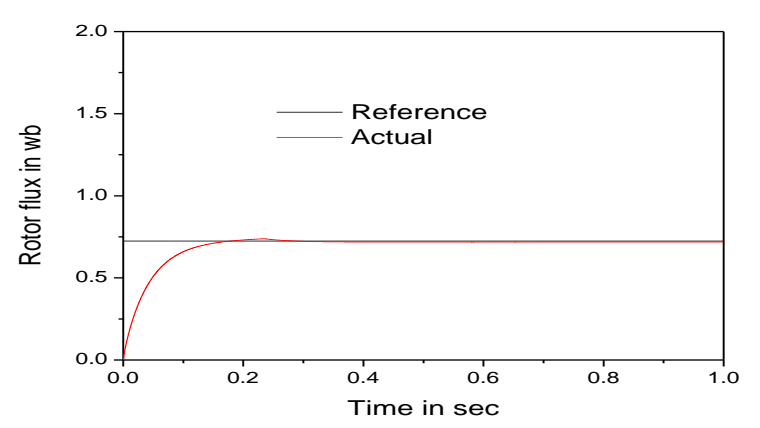

(c)

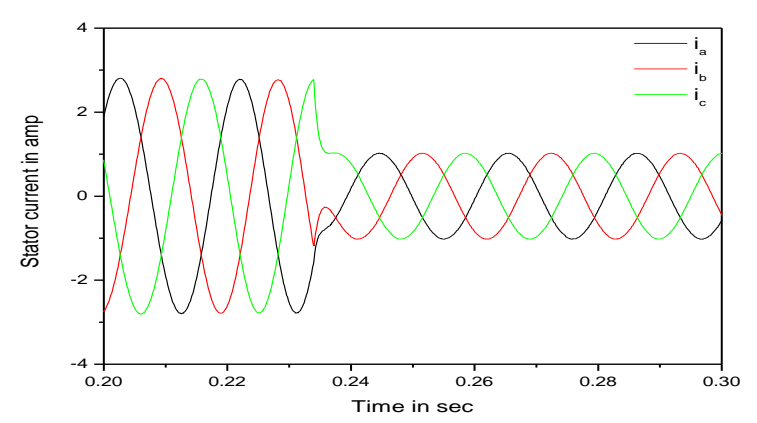

(d)

Fig. 5. (a) Simulated speed response, (b) developed electromagnetic torque, (c) rotor flux, and (d) stator current under transient and steady-state condition.

\section{Performance Under Different Operating Conditions}

The performance of the induction motor drive under different operating conditions was also investigated in order to verify the robustness of the proposed control scheme. The performances of the drive system for various changes in speed with no load are shown in Figs 6(a), 6(b), and 6(c). From Fig. 6(a) it is observed that the proposed control scheme follows both the forward and reverse direction reference track quickly with negligible torque and flux ripple. The control scheme also follows the step change in speed and ramp change in speed reference track accurately with negligible torque and flux ripple and shown in Fig. 6(b) \& 6(c) respectively. Effectiveness of the proposed control scheme was also tested by applying and reducing load torque in step and shown in Fig. 6(d). The load torque of the motor was suddenly increased from $0 \mathrm{~N}-\mathrm{m}$ to $4.0 \mathrm{~N}-\mathrm{m}$ at $\mathrm{t}=0.5$ second, then decreased to $2.0 \mathrm{~N}-\mathrm{m}$ at $\mathrm{t}=1.0$ second and again to 1.0 $\mathrm{N}-\mathrm{m}$ at $\mathrm{t}=1.5$ second. No fall and oscillation in speed is noticed due to this load torque disturbance. Also the developed electromagnetic torque and the rotor flux are found almost ripple free.
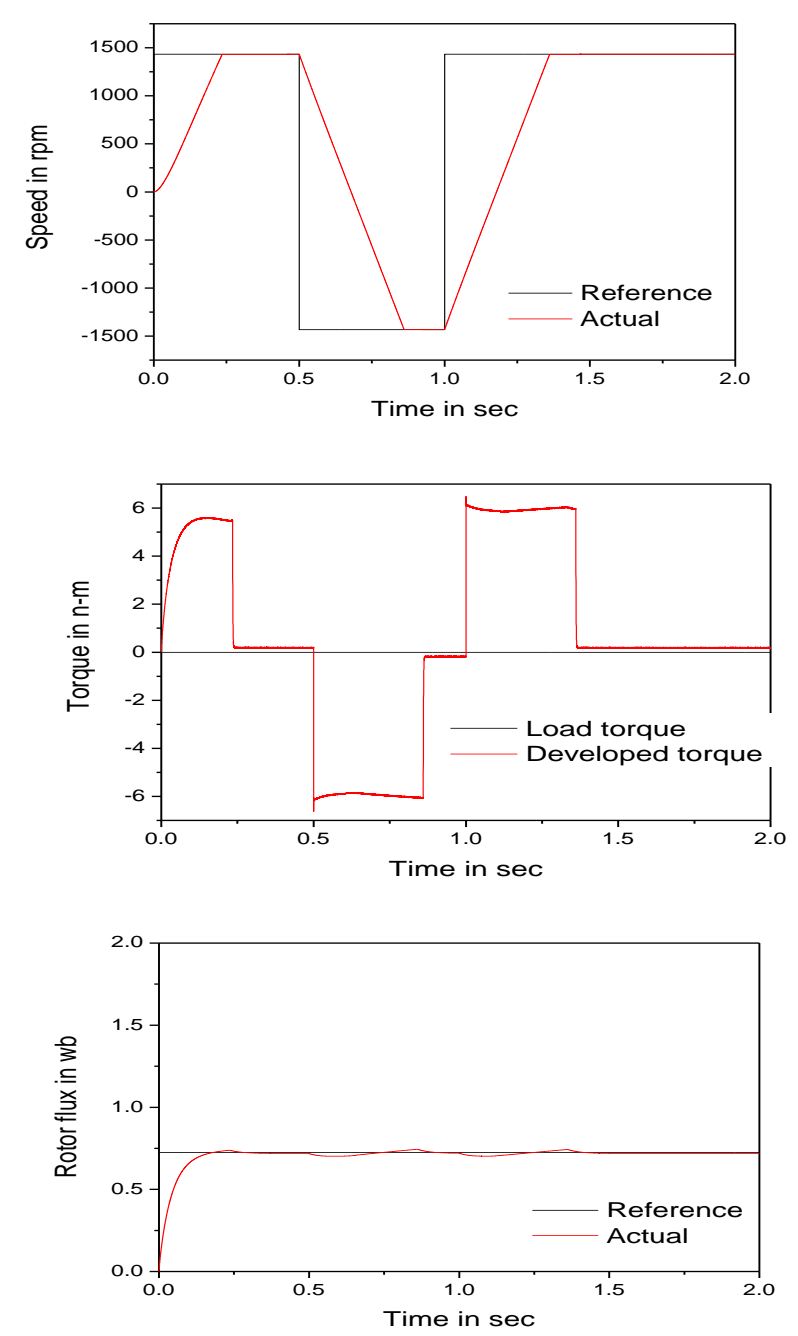

(a)
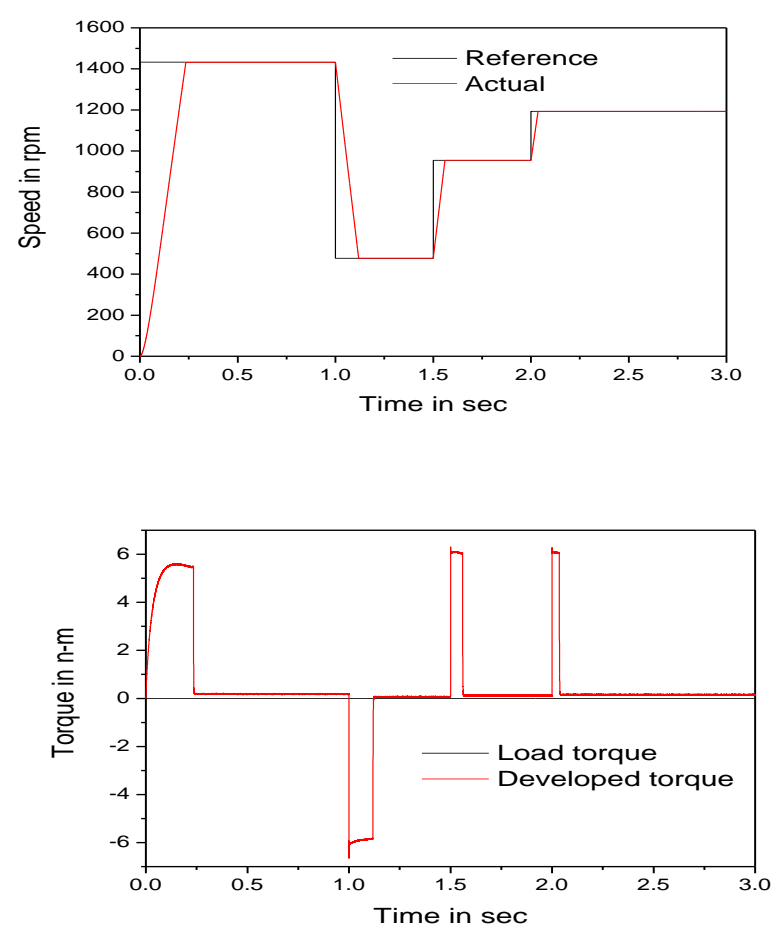


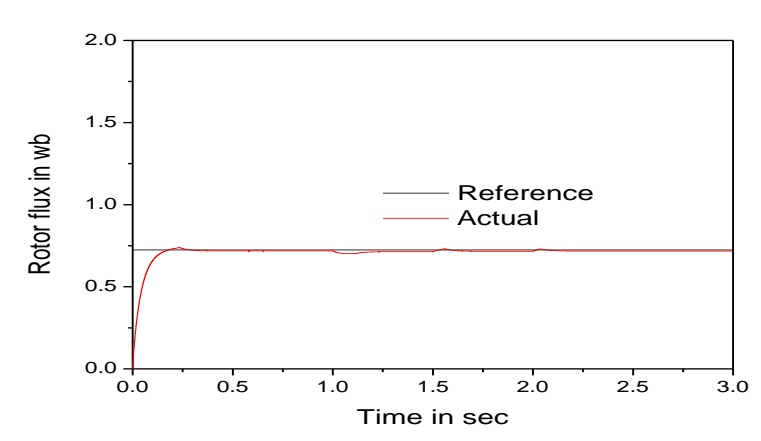

(b)
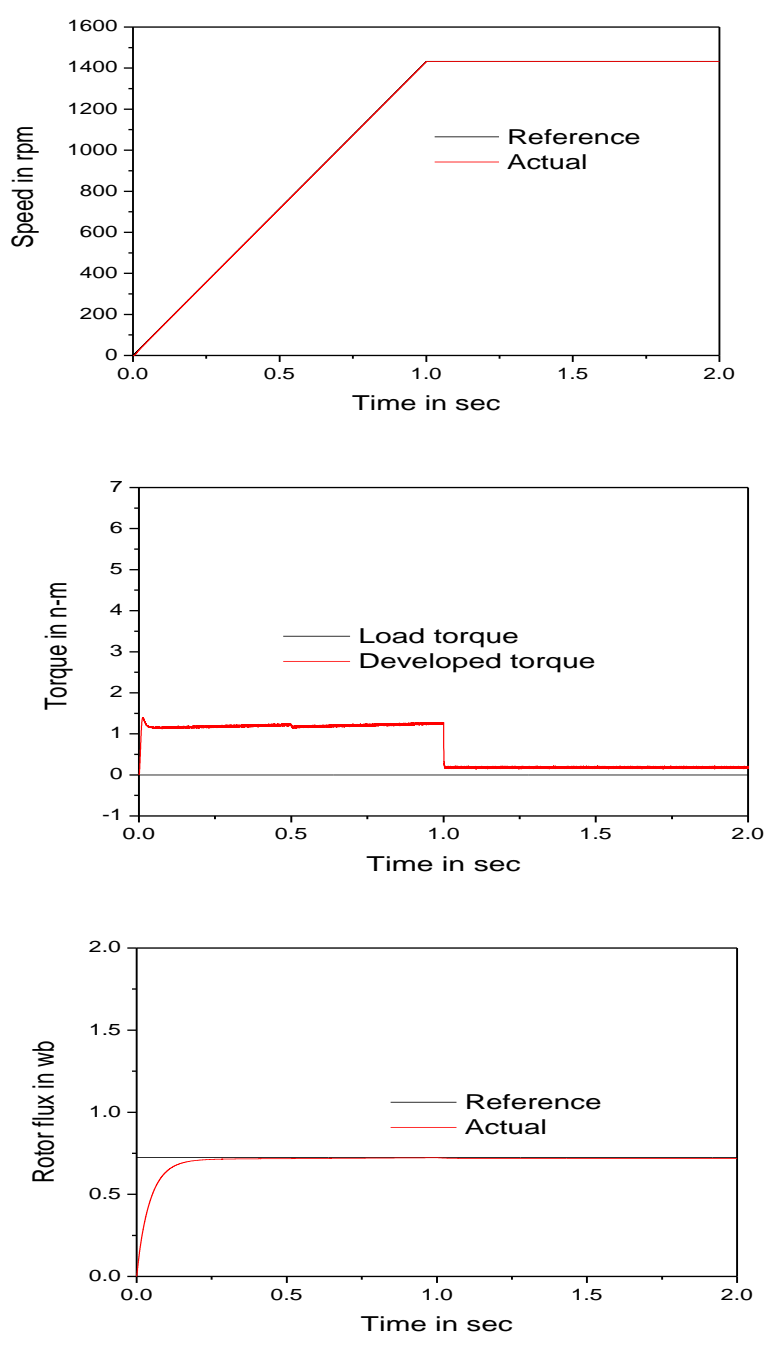

(c)

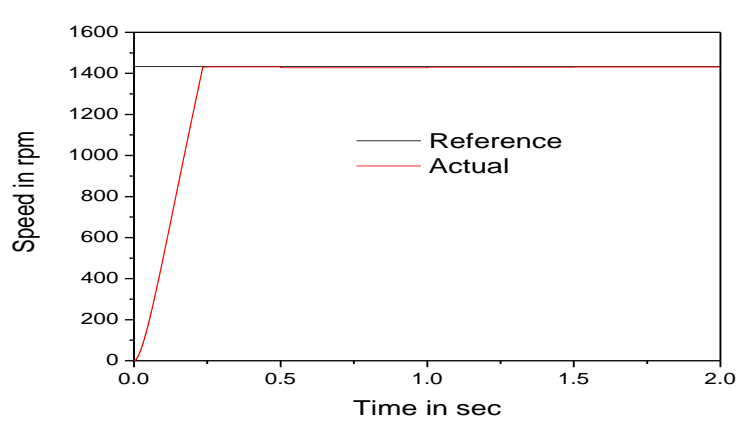

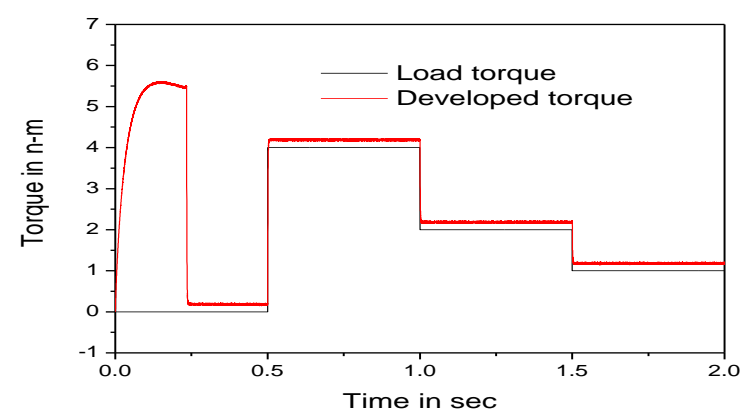

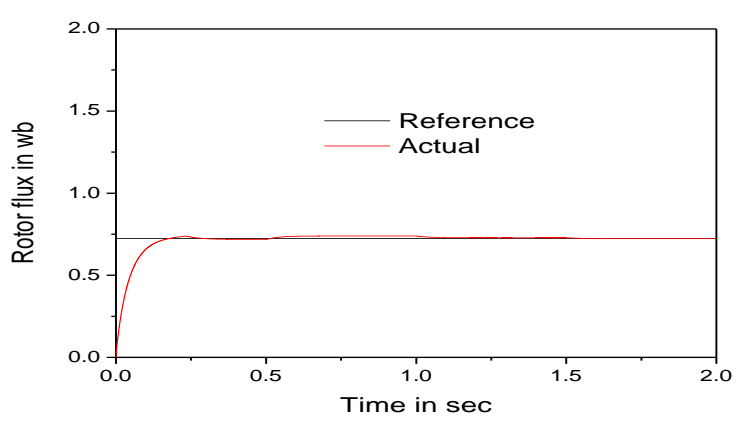

(d)

Fig. 6. Performances of the induction motor drive with (a) speed reverse, (b) step change in speed, (c) ramp change in speed, and (d) step change of load.

In order to obtain a high performance induction motor drive, its controller should be insensitive with the machine parameter deviation. The insensitivity of the proposed controller due to increase of both stator and rotor resistance of the machine up to $100 \%$ from its nominal value at $\mathrm{t}=1.0$ second can be visualized from Fig. 7(a) and 7(b) respectively.
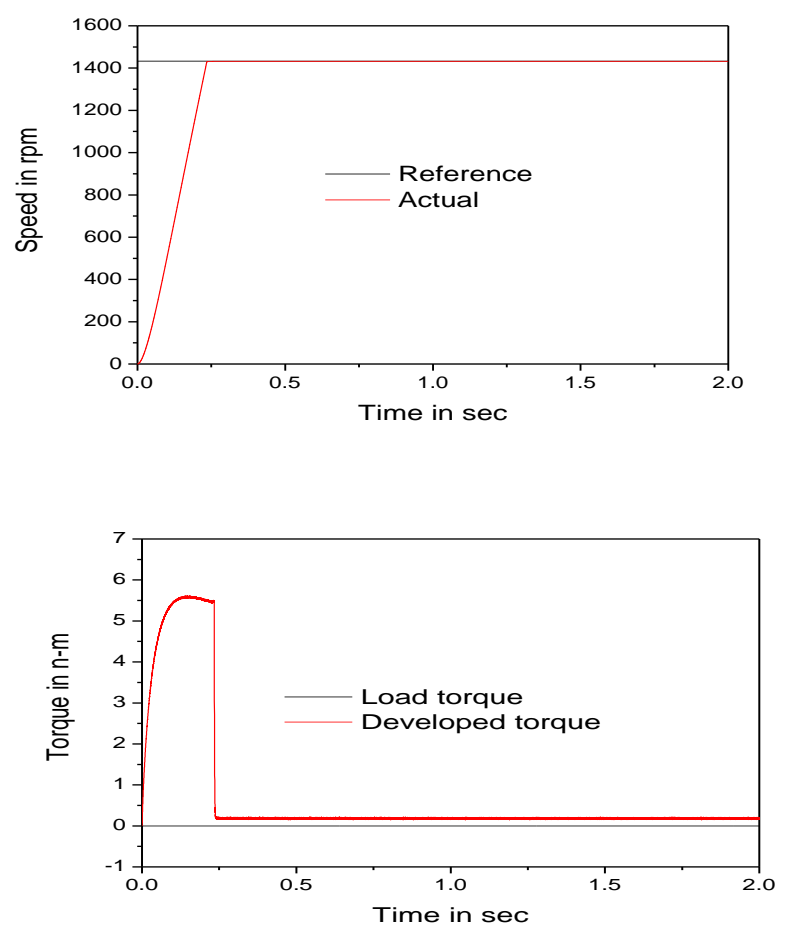


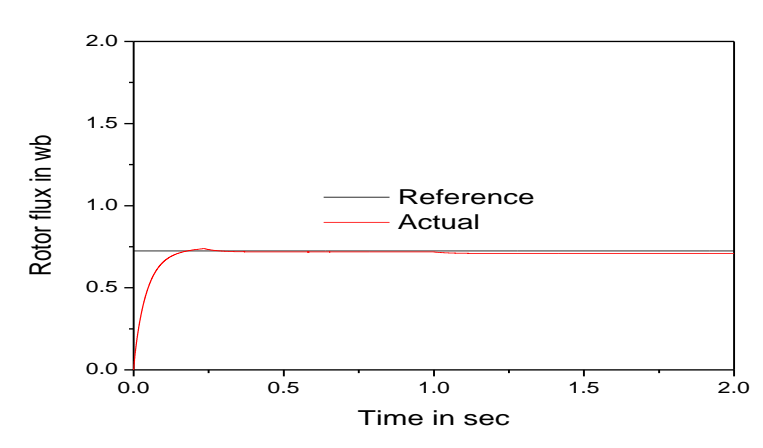

(a)
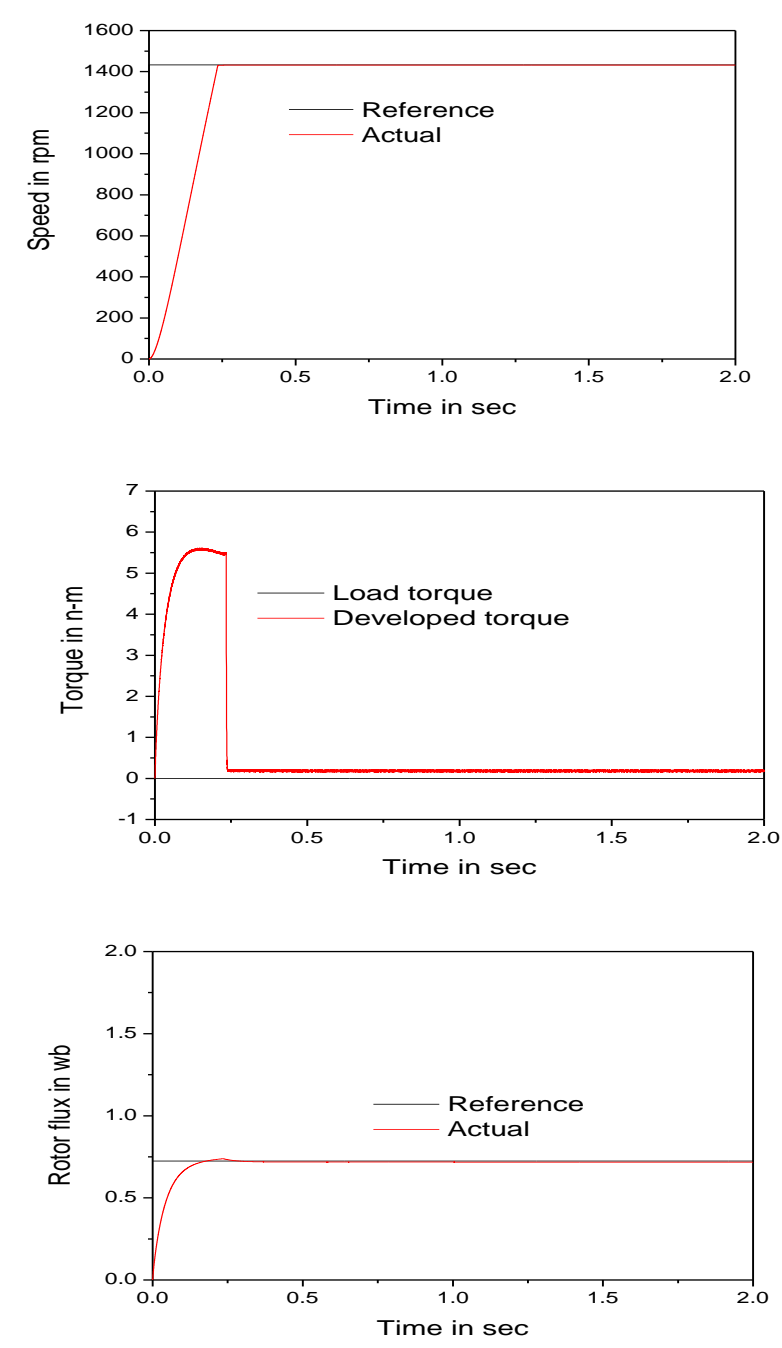

(b)

Fig. 7. Performances of the induction motor drive for change in stator and rotor resistances with (a) $R_{s}=2 R_{s}^{*}$, and (b) $R_{r}=2 R_{r}^{*}$ at $\mathrm{t}=1$ second.

There is some instrumental error always present in physical system. For the robustness test $10 \%$ instrumental error was introduced to reference voltage vectors. The performance of the motor speed, developed electromagnetic torque, and the rotor flux are shown in Fig. 8. It can be observed that the performances are similar to the motor starting performance. So depending on the performance, it can be concluded that the proposed control scheme is computationally efficient.
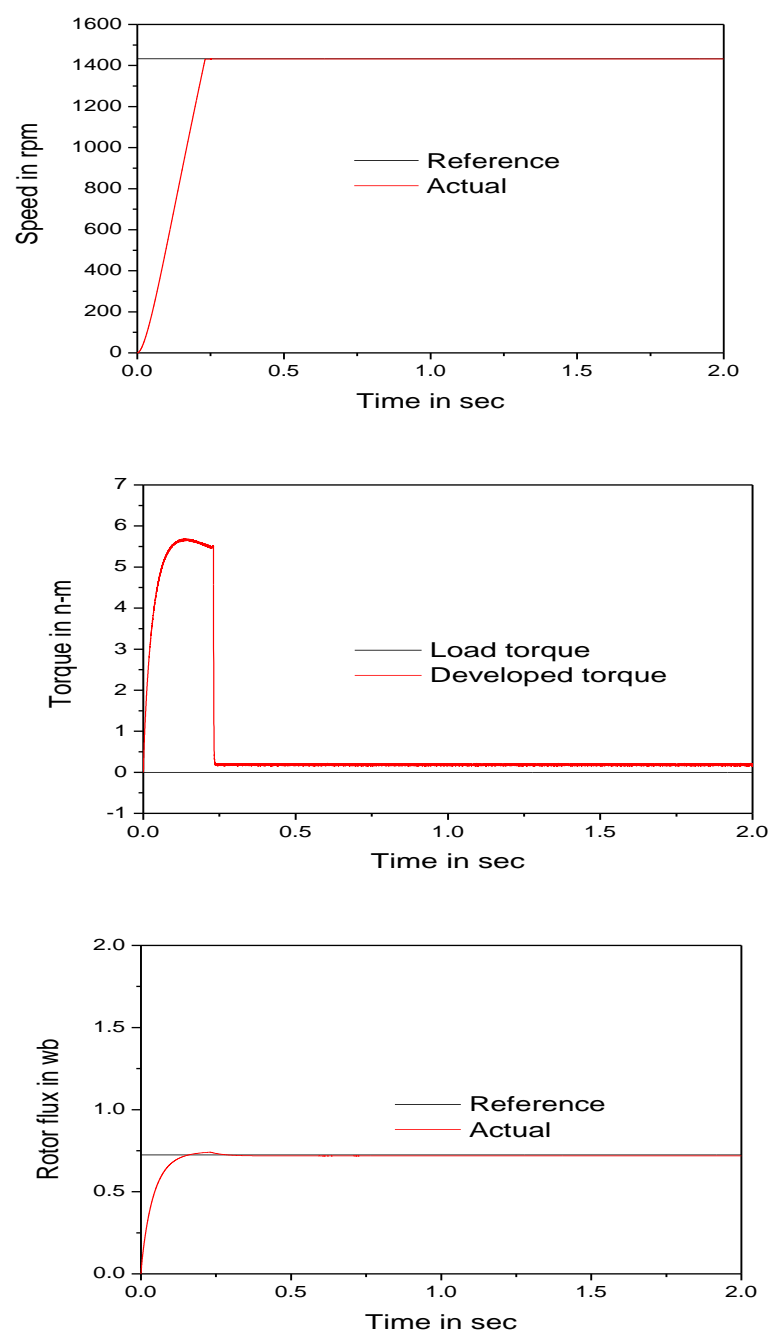

Fig. 8. Performances of the induction motor drive under computational errors present in the physical system.

\section{CONCLUSIONS}

This paper presents a new high performance control methodology for position sensorless induction motor drive with reduced torque and flux ripple. The results obtained and presented in this work indicate that the proposed control strategy produces very fast response of the induction motor drive and realizes almost ripple free operation in torque, stator current, and rotor flux. It is also observed that the proposed drive with CRTRL based flux estimator is capable to estimate stator flux and rotor position both in steady-state and transient conditions accurately. The drive is also robust to load disturbances, parameter variations, and different speed tracking conditions. Due to its simple structure it can be easily implemented on available embedded DSP's, thus will find many practical applications.

\section{APPENDIX}

Parameters of induction motor for simulation

\begin{tabular}{|l|c|}
\hline Parameter & Value \\
\hline Rated power $(\mathrm{KW})$ & 0.75 \\
Rated voltage $(\mathrm{V})$ & 415 \\
Rated current $(\mathrm{A})$ & 1.8 \\
Rated speed $(\mathrm{rad} / \mathrm{s})$ & 150 \\
Stator resistance $(\Omega)$ & 13.25 \\
\hline
\end{tabular}




\begin{tabular}{|l|c|}
\hline Rotor resistance $(\Omega)$ & 16.818 \\
Mutual inductance $(\mathrm{H})$ & 0.7114 \\
Stator self inductance $(\mathrm{H})$ & 0.7359 \\
Rotor self inductance $(\mathrm{H})$ & 0.7359 \\
Moment of inertia $\left(\mathrm{Kg}-\mathrm{m}^{2}\right)$ & 0.0075 \\
Damping coefficient $(\mathrm{Nm}-\mathrm{sec} / \mathrm{rad})$ & 0.00107 \\
Number of pole pairs & 2 \\
\hline
\end{tabular}

Saturation characteristic for induction machine: Mutual inductance,

$$
\begin{aligned}
& L_{m}=f\left(i_{\text {mag }}\right)= \\
& b_{0}+b_{1} i_{\text {mag }}+b_{2} i_{\text {mag }}^{2}+b_{3} i_{\text {mag }}^{3}+b_{4} i_{\text {mag }}^{4}+b_{5} i_{\text {mag }}^{5} \\
& b_{0}=0.9328 ; b_{1}=0.27058 ; b_{2}=-0.95898 ; b_{3}=0.54123 ; \\
& b_{4}=-0.5479 ; b_{5}=-0.01859
\end{aligned}
$$

\section{REFERENCES}

[1] Jun-Koo Kang, and Seung-Ki Sul, "Analysis and prediction of inverter switching frequency in direct torque control of induction machine based on hysteresis bands and machine parameters," IEEE Trans. on Ind. Electron., vol. 48, no. 3, June 2001, pp. 545-553.

[2] D. Casadei, G. Serra, A. Tani, L. Zarri and F. Profumo, "Performance analysis of a speed-sensorless induction motor drive based on a constant switching frequency DTC scheme," IEEE Trans. on Ind. Applicat., vol. 39, March/April 2003, pp. 476-484.

[3] Luis Romeral, Antoni Arias, Emiliano Aldabas, and Marcel. G. Jayne, "Novel direct torque control (DTC) scheme with fuzzy adaptive torque-ripple reduction," IEEE Trans. on Ind. Elecron., vol. 50, no. 3, June 2003, pp. 487-492.
[4] Nik Rumzi Nik Idris and Abdul Halim Mohammed Yatim, "Direct torque control of induction machines with constant switching frequency and reduced torque ripple," IEEE Trans. on Ind. Elecron., vol. 51, no.4, Aug. 2004, pp. 186-196.

[5] Manuele Bertoluzzo, Giuseppe Buja and Roberto Menis, "Direct torque control of an induction motor using a single current sensor," IEEE Trans. on Ind. Elecron., vol. 53, no.3, June 2006, pp. 778-784.

[6] K. B. Lee, J. H. Song, I. Choy and J. Y. Yoo, "Torque ripple reduction in DTC of induction motor driven by three-level inverter with low switching frequency," IEEE Trans. on Power Electron., vol. 17, March 2002, pp. 255-264,.

[7] Ehsan Hassan Khan and Davood A. Khaburi, "DTC-SVM scheme for induction motors fed with a three-level inverter," World Academy of Science and Technology, vol. 44, 2008, pp. 168-172.

[8] M. Schroedl, "Sensorless Control of AC Machines at Low Speed and Standstill Based on the "Inform" Method", IEEE IAS Annual Meeting, 1996, pp. 270 - 277.

[9] P. L. Jansen and R. D. Lorenz, "Transducerless Position and Velocity Estimation in Induction and Salient AC Machines", IEEE Trans. on Ind. Applicat., vol. 31, no. 2, March 1995, pp. 240 -247.

[10] J. Cilia, G. M. Asher, K. J. Bradley, and M. Sumner, "Sensorless Position Detection for Vector Controlled Induction Motor Drives using an Asymmetric Outer-Section Cage," IEEE trans. on Ind. Applicat., vol. 33 , no. 5, October 1997, pp. $1162-1169$.

[11] J. Holtz, "Sensorless Position Control of Induction Motors - An Emerging Technology," IEEE Trans. on Ind. Electron., vol. 45, no. 6 , Dec. 1998 , pp. 840 - 852 .

[12] N. Teske, G. M. Asher, K. J. Bradley, and M. Sumner, "Sensorless Position Control of Induction Machines using Rotor Saliencies under Load Conditions," EPE 99, September 1999.

[13] Jae Ho Chang, and Byung Kook Kim, "Minimum-Time Minimum Loss Speed Control of Induction Motors Under Field-Oriented Control," IEEE Trans. on Ind. Elecron., vol. 44, no.6, Dec. 1997, pp. 809-815.

[14] Md. Abdur Rafiq, Naruttam Kumar Roy, and B. C. Ghosh, "An Improved Induction Motor Rotor Flux Estimator Based on Correlated Real Time Recurrent Learning Algorithm," Proc. of international conf. pasco, Andra University, Visakhapatnam, Ap, India, March 2008. 